AIAA 2000-3403

Observations on Rotating Cavitation and Cavitation Surge From the Development of the Fastrac Engine Turbopump

T. Zoladz

NASA / George C. Marshall Space Flight Center

$36^{\text {th }}$ AIAA/ASME/SAE/ASEE Joint Propulsion Conference

17-19 July 2000

Von Braun Civic Center

Huntsville, Alabama

For permission to copy or to republish. contact the American Institute of Aeronautics and Astronautics. 1801 Alexander Bell Drive, Suite 500, Reston. VA. $20191-4344$. 


\title{
OBSERVATIONS ON ROTATING CAVITATION AND CAVITATION SURGE FROM THE DEVELOPMENT OF THE FASTRAC ENGINE TURBOPUMP
}

\author{
T. Zoiadz
}

NASA / George C. Marsnall Space Flight Center

Huntsville. Alabama

\begin{abstract}
Observations regarding rotating cavitation and cavitation surge experienced during the development of the Fastrac engine turbopump are : scussed. Detalled observations acquired from me analvsis of both water flow and hquid oxvgen ¿st data are offered in this paper. Scaling and zeneral comparison of rotating cavitation between :ater llow and liquid oxygen tesing are iscussed. Compiex data features linking the ocalized rotating cavitation mechanism of the nducer to system surge components are jescrioed in detall. Finally a desciotion o! a imped-parameter nvarauilc system model leveloped to better uncerstand opserved data is given.
\end{abstract}

\section{Nomenclature}

- ivnchronous oscillation taing cavitation oscillation

@ dimensional pump compliance

$\checkmark$ dimensionless pump compliance

" $1^{\circ}$ dimensional mass flow gain factor

.1 imensioniess mass flow rain :actor

iss istion specific speed

- nlet tip tlow coefficient

- nlet cavitation number

- inducer tip cavitation numoer

is stage nead coefficient

\section{i. neroduction}

During the develooment of the nigh speed iroopump for the 60.000 pound thrust Fastrac -ocket engine. complex unsteady flow and shaft vibration due to rotating cavitation have been observed. The bipropellant pump (Figure 1) with both a single-stage LOX (shown with axial inlet) and RP inducer-impeller sharing the same drive shaft exhibits independent cavitation induced super-syncnronous oscillations concurrently during ominat oderation.

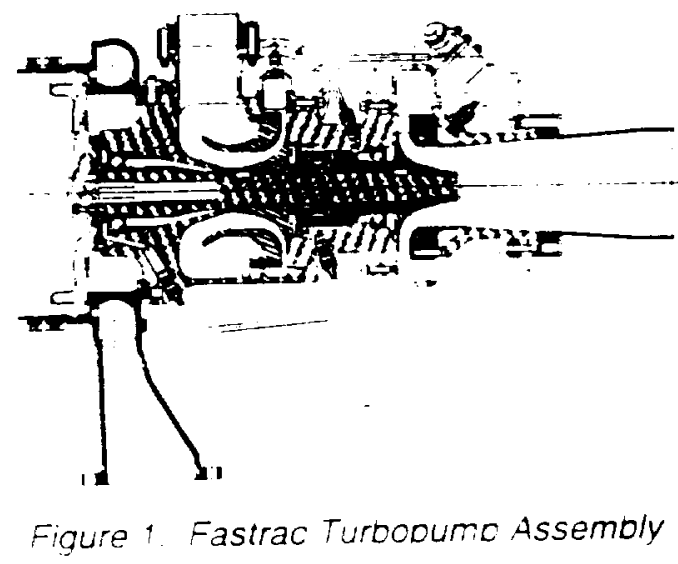

This cocument attempts to summarize major observations regarding the Fastrac LOX turbopump rotating cavitation anomaly and relay them to a turbomachinery community that must trequently contend with hydraulic system nstabilities inquced by cavitatıng pumos. Joservations nave been derived from LOX oumD super-scale model water flow tesung and turbopump component level hottire test. Characterization and abatement of the cavitation instability continue to be critical issues in the development and certification of the Fastrac engine due to leading edge blade deformations found in both the initial aluminum water flow test article and subsequently in a component level test inducer. Figures 2 and 3 show the damaged leading edge regions in the water flow aluminum and the LOX K-Monel inducers respectively. 


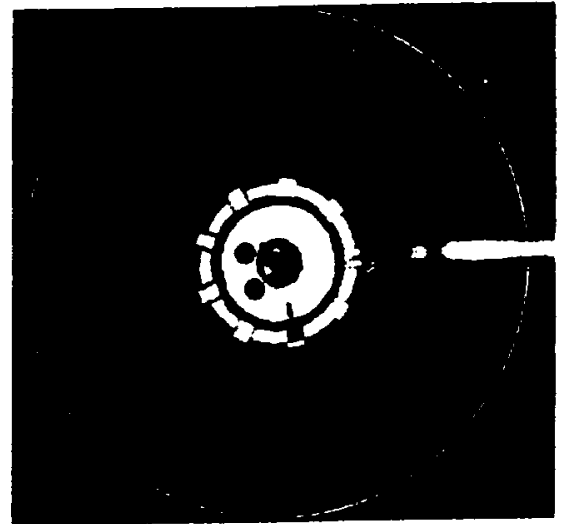

Figure 2. Failed Aluminum Inducer

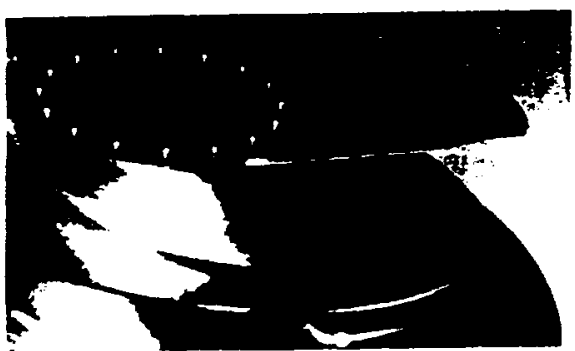

Ggure :. LX Inducer with Slight Leading Edge Deformation

Uns:eadv llow analysıs of the Fastrac engine -OX turoodumo has benerited from multipie jources or experimentalitest cata of the comblex. nstadiur. Water low rig testing of the LOX Dumb. illiated :o expermentallv veriv suction vertormance. nas provided valuade insignt into :he anomaly and produced the first evidence of the severity of the rotating cavitation with the failure of the original aluminum superscale LOX

nducer-impeller. Figure 4 is a loint

me-frequency mapoing of the oscillation taken "om water tlow: ated ilow condtion $10=0.135 i$ and a shaft soeed I 5000 RPM.

The inducer inlet fluctuating pressure data shows the development of the rotating cavitation oscillation, denoted as "rc" in the figure, during an inlet pressure ramo tesi (suction pressure Jecrease going into Dage) at constant -ow-to-soeed ratio. In-depth discussion of the spectral trending will be offered in subsequent sections of this overvew. The experimental latitude offered by the water rig testing has been crucial to the characterization of the oscillation.

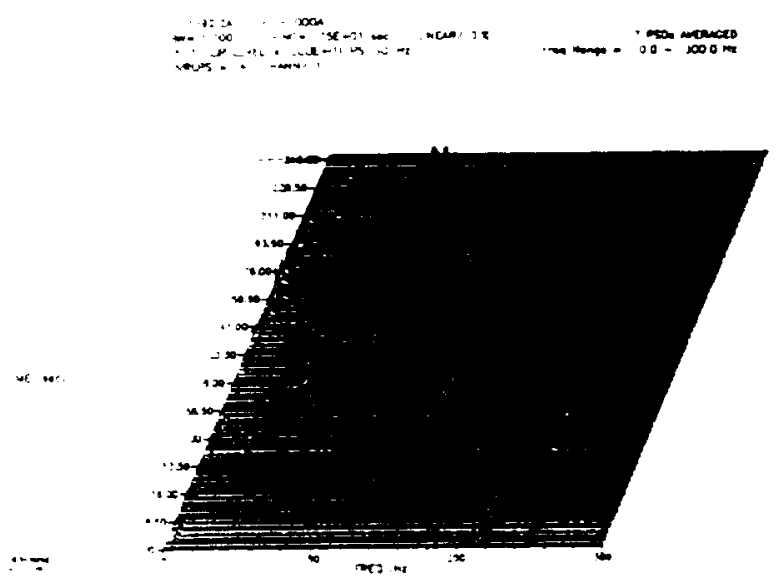

Figure 4. Waterfall Plot of Inducer Inlet Fiuctuating Pressure rom Water Flow Test

Several of the features of the Fastrac :urbopump rotating cavitation have been documented by many researchers involved in the development of other high speed rocket engine iurbomachinery. " Tsujimoto. et al.. provided an excellent overview of inducer rotating disturbances encountered during the develooment of the LE-7 LOX turbopump. A majoritv of the spectral components snown in Figure 4 have counterparts cescribed in the LE-7 cavitation oscillation overview.

Rotating cavitation nas sroven to be more than just a nuisance to the Fastrac engine development program. Along with deforming inducer leading edges, pump cavitation has hampered characterization of the turbopump vibration environment due to saturation of accelerometers and signal conditioning. Excitation of both LOX and RP feed-svstem nydrauiic modes ov the active inqucers nas aiso complicated engine calibration efforts by nindering accurate propellant flow measurement.

\section{Rotating Cavitation and Cavitation Surge Data Observations}

\section{Rotating Cavitation}

As noted previously, water flow testing offered several experimental opporiunities not avallable in 
the LOX environment. This included the accessibility of high frequency instrumentation locations and the ability to easily manipulate pump inlet hydrodynamic condition, i.e. Nss (suction specific speed) and $\theta$, in the water flow loop (Figure 5). Flush mounted fluctuating pressures at the inducer inlet plane approximately 0.3 inducer diameters upstream of the blade leading edge (instrumentation plane 1000, Figure 5) were used to establish the rotational character of the oscillations shown in the joint time-frequency plot of Figure 4. Hannover plotting of inducer inlet fluctuating pressure relative phase information was used in determining cell number and propagation direction of the major spectral components.

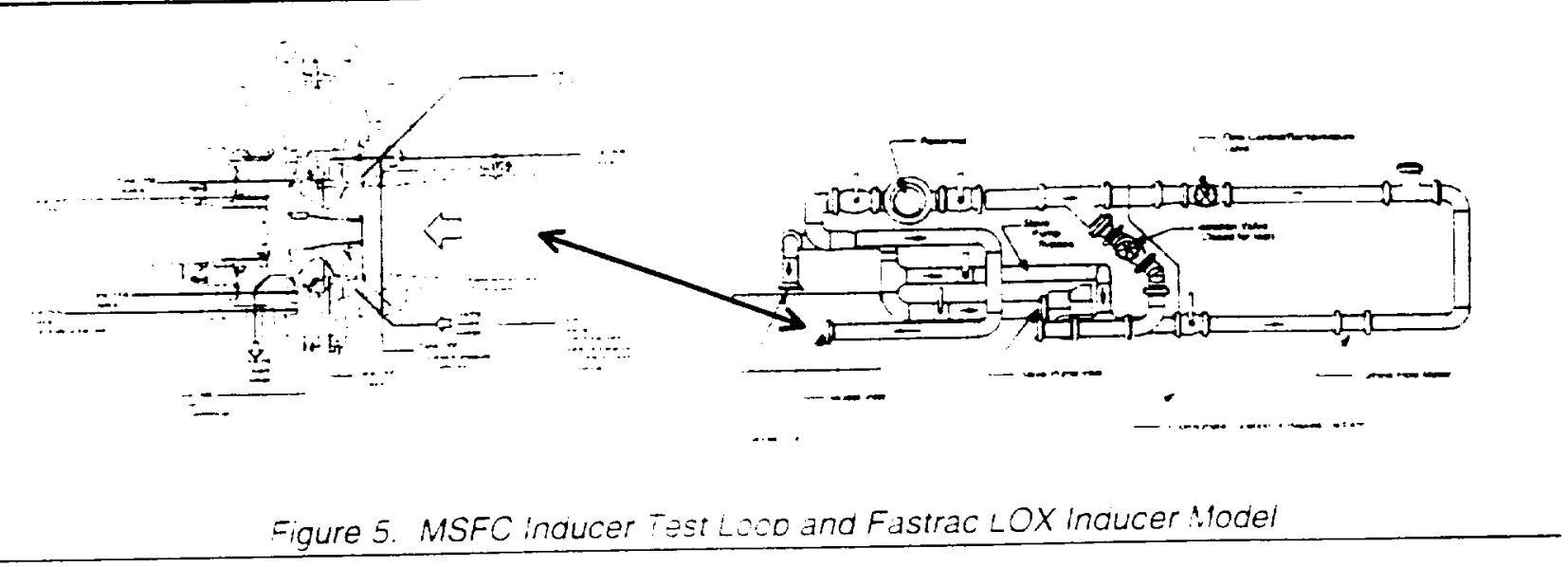

As expecied. the peaks denoted as " $3 N$ " and $N^{\prime \prime}$, are inree and single cell disturbances. -espectively. Cross-cnannel onasing at the nducer inlet dane confirm their lock-in in a rotational sense) to the three-bladed inducer. The peak denoted as rc in Figure 4 , is a one-celled disturbance propagating in a forward direction. 1.e .n the same direcion as the rotor. at a slightly super-synchronous rate. No significant loss in zumping efficiency was noted in water flow sucilon Dertormance mappings untıl the appearance or the synchronous oscillation. N, where stage head coefficient, $\Psi$, dropped approximately 2 percent from the non-cavitated (< 15000 Nss) water flow value of 0.40 .

The peak cenoted as "ff" in Figure 4 is inougnt to be a rotatıng disturbance of hign cell count related to backflow vortices. Phasing suggests that the low amplitude oscillation is an eight-cell disturbance with a propagation velocity of approximately $0.32 \mathrm{~N}$. The cell train propagation rate and high cell count compare well to rotating backflow disturbances characterized in Reference 3. However. Inlet plane phase mapping vas not of high enough fidelity to confirm propagation direction and the nign cell count of $\$ 1$.

Figure 6 shows ooth normatized irequency and amplitude of $3 N$. rc, and $N$ versus Nss at the $90 \%$ rated flow condition from both water flow and LOX testing. Comparison at this slightly off-nominal flow condition was selected since a majority of the LOX test data was acquired at the $30 \%$ rated flow. In the ligure. ciosed svmbols denote normalized water cata while the arger open symools represent LOX. The frequency of the rotating cavitation component, rc. is normalized by synchronous frequency while all amplitudes are scaled by impeller tip dynamic sressure. Normalized trequency for rc ranges rom $1:$ to $: .25$ and the cecreasing irend with Nss compares well between LOX and water test. Likewise, there is good comparison between normalized amplitudes of the rc and $N$ components as well as the critical Nss at which rc transitions into the synchronous response. A normalized $3 \mathrm{~N}$ amplitude is not shown for LOX since the furbooump acquired no appreciable steady-state operation at low Nss. I.e. iess than 12 kNss. 


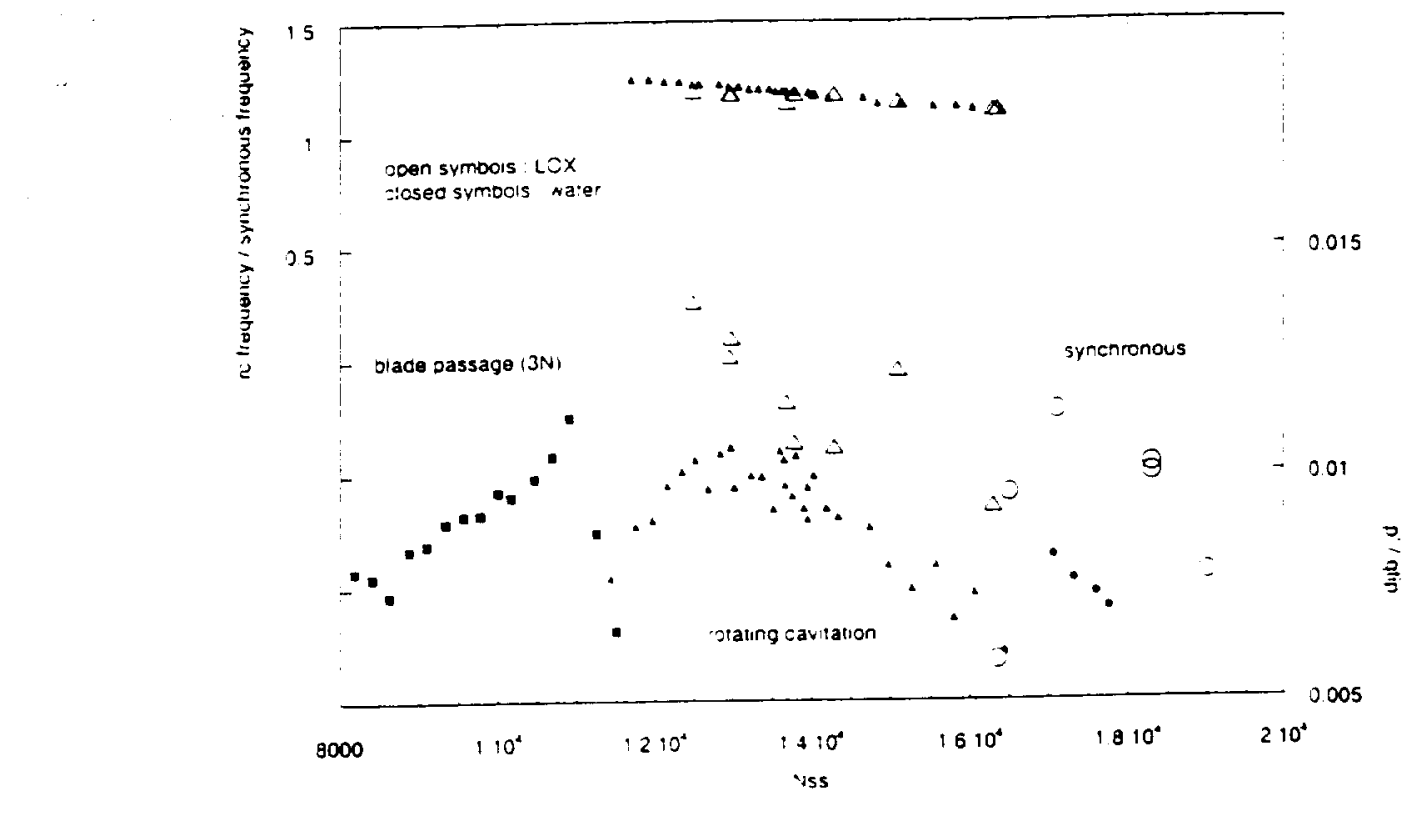

Figure j. Normalized Frequency ana Amollude or Malor Fastrac LOX Inqucer Oscillations from Both LOX ana Water Testing

\section{Cavitation Surge}

During water flow testing of the suderscaie Fastrac LOX inducer model. sirong pumo-taciuty coupling was experienced. Figure 7 is a wateriall plot of an upstream (approxımately 1.5 inlet diameters from inducer) unsteady pressure. Amolitude scale is equivalent to that of the incucer ilet wateriall plot of Figure 4 . The dominant oscillations registered at this upstream location are $3(r \mathrm{C}-N)$ and the component denoted as " 2 ". Further analysis into phasing and the high frequency content of measured fluctuating pressure both at the inducer inlet plane and elsewhere in the water flow loop revealed nteresting attributes of the $3(\mathrm{rc}-\mathrm{N})$ comoonent.

Figure 8 is a series of waveforms $10-.0 \mathrm{kHz}$ Jandwidth) across several locations over 15 cycles of $3(\mathrm{rc}-\mathrm{N})$. In sequence from top to bottom are upstream fluctuating pressure, inlet fluctuating pressure, inlet fluctuating pressure at an alternate circumferential location, and finally radial acceleration measured on the pump nousing. Clearly, the dominance of the $3(\mathrm{rC}-\mathrm{N})$ $n$ the upstream pressure is shown. Likewise the complexity of the nonlinear interaction between the rotating cavitation component and the synchronous rate is very evident in the two Inducer nlet pressures.
While the rotation-induced delay of the higher :requency rotating cavitation wavelet is easy to alscern between the two inlet Dressures, the underlying $3(\mathrm{rC}-\mathrm{N})$ wave appears to be in phase. The inducer inlet plane transier function of Figure 9 confirms this unique phasing at the requency of $3(\mathrm{rc}-N)$. Relative phase at the uscillation freauency is zero with a coherence of hearly unity. Similar phasing and coherence for $3(r c-N)$ were shown witn the alternate inducer niet cross-channel pair.

\section{Before discussing possible physical} implications of the complex component $3(\mathrm{rc}-\mathrm{N})$, some observations on the transient envelope of :he monitored fluctuating pressures are now jifered. Figure 10 displays a nigh-pass tiltered version of Figure 8 . The data were high-pass filtered at $2 \mathrm{kHz}$ to safely exclude $\mathrm{rc}$ and synchronous activity. Of interest in this series of filtered waveforms is the obvious synchronization of wideband bursts at the rate of $3(\mathrm{rc}-\mathrm{N})$ across all fluctuating pressures and monitored pump vibration. Envelope spectral analysis of these vaveforms has confirmed this synchronization. 


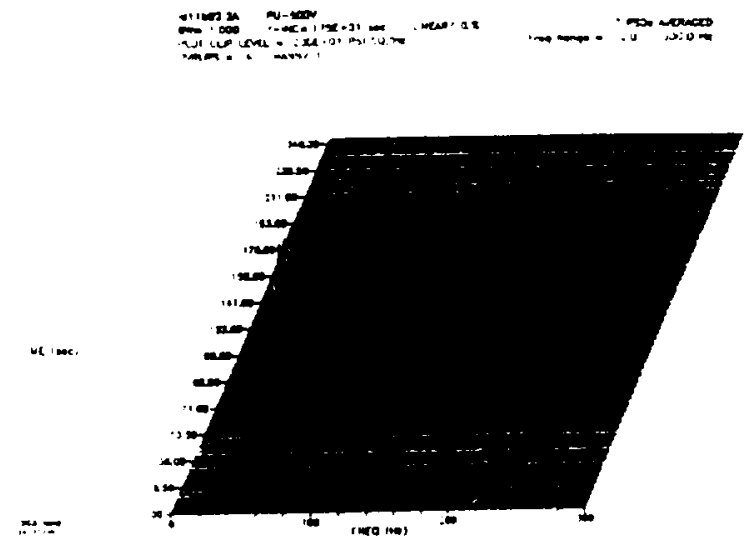

Figure 7. Waterfall Plot of Upstream Fluctuating Pressure from Water Flow Test

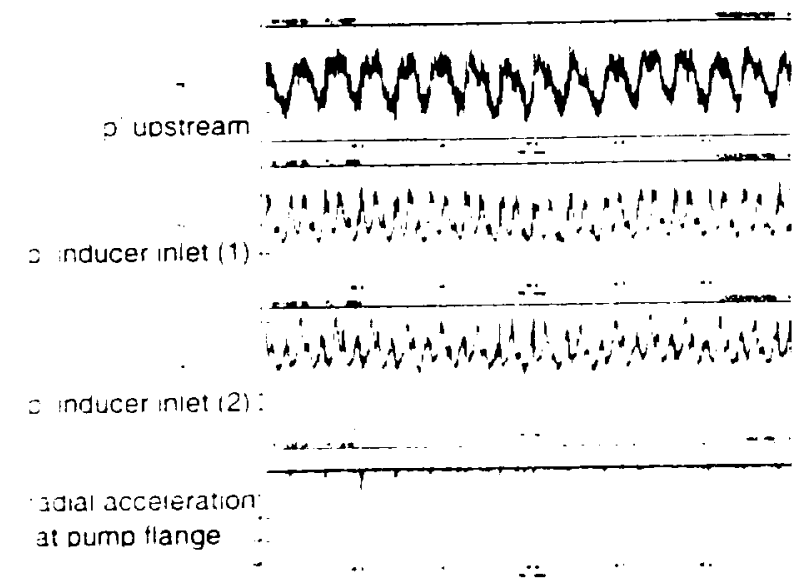

Figure 8. Multiple Location Pressure and vibration Wavetorms During Rotating Cavitation Over 15 Crcles of $3(r \mathrm{C}-\mathrm{N})$

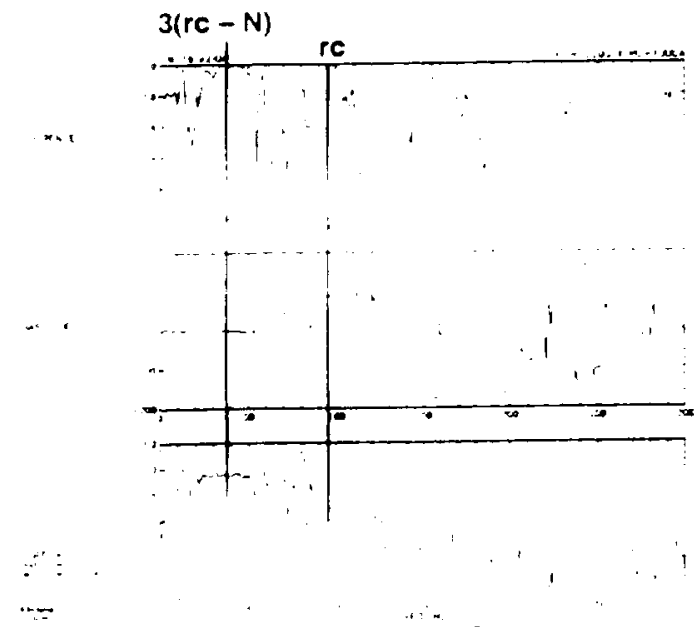

Figure 9. Inducer inlet Pressure Cross-Channel Coherence. Phase, and Gain During Rotating Cavitation

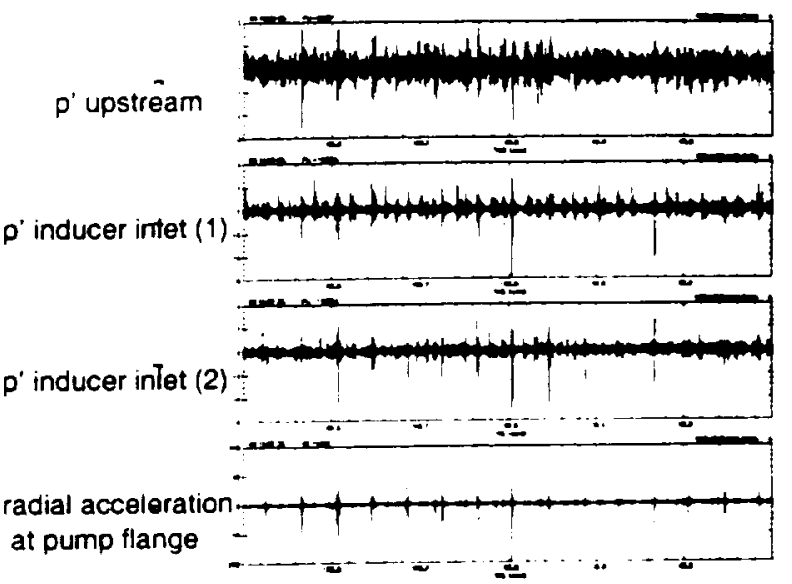

Figure 10. Multiple Location Filtered Pressure and Vibration Waveforms During Rotating Cavitation Over 15 Cycles of $3(r c-N)$

The unique phasing is thought to reflect the complex pnysical relationship between the localized inducer rotating cavitation disturbance and the more global cavitation surge instability. A component similar to the $3(\mathrm{rc}-\mathrm{N})$ has been documented by Tsujimoto and fellow researchers. In their effort. a cavitation surge mode was dentified at a trequency corresponaing to $(\mathrm{rc}-\mathrm{N})$. The frequency variation of the Ir cavitation surge at : Imes lost correlation with those of the $\mathrm{rC}$ and $\mathrm{N}$ components. In Fastrac LOX inducer irater flow testing, correlation of the cavitation surge mode at $3(\mathrm{rc}-N)$ with the rotating cavitation and synchronous components was maintained.

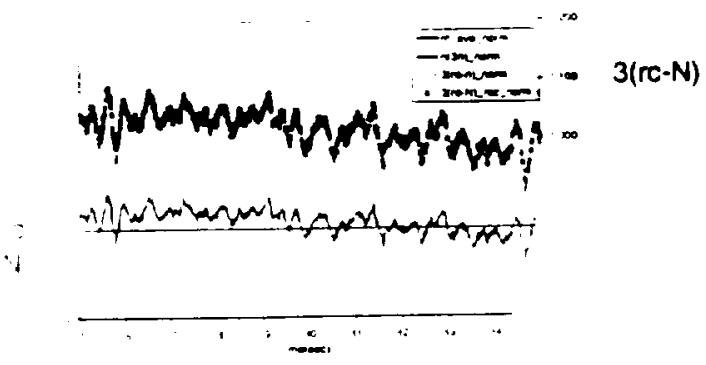

Figure 11. Instantaneous Frequency Correlation of Cavitation Surge with Rotating Cavitation and Synchronous - Water Flow

Figure 11 overlays the normalized instantaneous frequency variation of a composite $3(\mathrm{rc}-N)$, developed from those of the rotating cavitation and synchronous components. with that of the actual cavitation surge component. Along 
with the overlay are displayed the variations (normalized by mean frequency over the entire record) of the rc and $\mathrm{N}$ components used in the construction of the composite $3(\mathrm{rc}-\mathrm{N})$.

Generalized Hypercoherence processing was used to develop the micro-frequency variations shown in Figure 11." The commercially-available signal processing package PC Signal, offered by Al Signal Research, provided the powerful diagnostic technique. The convincing match of the actual and reconstructed instantaneous frequencies of the cavitation surge oscillation indicates a high degree of synchronization between the rotating cavitation and the cavitation surge evident in the water flow circuit.

Instantaneous frequency analysis was not necessary in making this same assessment in the LOX environment. Figure 12 is a waterfall plot of inducer inlet pressure taken from the last hotfire of the slightly deformed hardware shown in Figure 3. The frequency axis has been scaled to facilitate comparison of water flow data with that of the LOX. During the first portion of the test, the LOX pump experienced an excursion into rotating cavitation (start +52 through 55 seconds). The LOX pump was operating at $88 \%$ of rated flow during the transient and traversed the critical Nss -egion of the rotating - synchronous cavitation joundary (Figure $6,-16 \mathrm{kNss}$ ). If the subsyncrionous component were locked into a irequency variation corresponding to $3(\mathrm{rc}-\mathrm{N})$ ) it would be a mirror image of the $(3 \mathrm{~N}-\mathrm{rC})$ component about the rotating cavitation trequency irace. The subsynchronous component does not :ollow inis variation during this excursion. However. this frequency correlation between the subsynchronous component and the synchronous and rotating cavitation disturbances increases toward the end of the transient. This varying degree of correlation, similar to that documented $\rightarrow$ the LE- $\bar{T}$ experimental effort. is thought to -oresent a reauced synchronization vetween ine ocalized inducer disturbance (rotating cavitation) and the overall hydraulic system (via the suspected cavitation surge mode). Envelope analysis of both inducer inlet unsteady pressure and pump housing vibration from LOX testing also exhibited a well-defined periodicity at the subsynchronous frequency.

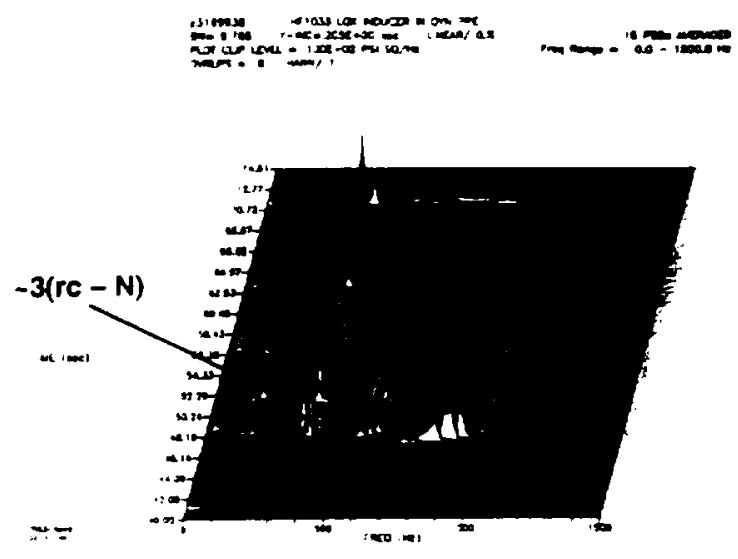

Figure 12. Water Plot of Inlet Fluctuating Pressure from Fastrac Turbopump Holfire

The spectral component labelled as 12 in Figure 4 showed little dependence on Nss and $\phi$ in water flow test. The frequency decreased slightly trom $4 \mathrm{~Hz}$ with increasing Nss. While the $3(\mathrm{rc}-\mathrm{N})$ mode appeared to be most active in the vicinity of the inducer, the 12 mode was much more distributed across the water flow loop.

\section{Hydraulic System Stability Analysis}

Analytic Model Overview

In an attempt to better uncerstand observed system couplings" between ire water flow LOX nducer and test facility. a lumoed parameter model of the MSFC Inducer Test Loop was developed. The analytic mocei is purely hydraulic in that no structural participation is considered. The model is composed of simple inertance. resistance, and compliance elements as well as additional terms specific to the pump component. These terms include the mass storage term due to variation in 0 . or mass flow gain factor, and a sumo pressure gain factor. "The pumo was nodeled with :wo characteristic equations consistent with the method of Oppenneim and Rubin used in their Pogo stability analysis of liquid rocket engines. 'Even though the the selected pump representation could be viewed as limited in light of the four-terminal pump dynamic transfer function experimental efforts performed at the California Institute of Technology, the treatment was felt sufficient for a first-orcer analysis of water flow system stability." 
The completed model consisted of 60 elements, which included lines, purely resistive losses (e.g. valves), accumulators, and the pump. The modeling of the hydraulic lines was consistent with that of Reference 7 . Wave speed reduction due to fluid air content and pipe wall compliance were considered and incorporated into the line elements. Pump gain and resistance were developed from steady pump performance characterizations of the inducer-impeller in water, while pump inertance was estimated using an empirical equation from Fenwick.

A strategy for setting pump compliance and mass flow gain factor in the analytic model was developed prior to anchoring the model to test data. First, dimensionless mass flow gain factor, $M$, was set by inlet cavitation number, $\sigma$, and an assumed dimensionless pump compliance. $\mathrm{K}$. using the recently published onset condition for both cavitation surge and rotating cavitation developed by Tsujimoto, Kamijo, and Brennen. $M$ and $K$ were converted to their dimensional torms. $M^{*}$ and $C$, respectively, in a manner consistent with scaling employed by Californa Institute of Technology researchers in their experimental determination of four-terminal oump yvnamic transfer functions

An Inıtial estımate of $K$ made using a mapping or an estimated $K$ and $M$ versus inducer tip cavitation number, $\sigma_{\text {, }}$, published by Brennen and Acosta for the Rocketdyne J2 LOX turbopump. Even though the parameters were anchored to inlet perturbation testing where fluctuating mass flows were neglected, the normalized mass storage terms were deemed valuable because the J2 LOX turbopump was known to exhibit a strong supersynchronous oscillation thought to be rotating cavitation. ${ }^{\text {. } 12}$ The current shrouded version of the J2 LOX turbopump integrated with :he Rocketdvne XRS-2000 Aerosolke engine aiso exnibits rotating cavitation along with (rc $-\mathrm{N})$.

The experimental data attribute which drove analytic model adjustment of $\mathrm{K}$ (and subsequently $M)$ was variation of the $3(\mathrm{rc}-N)$ frequency observed with water flow suction pressure ramping. Figure 13 shows the reference frequency tracking taken from water flow test along with the last iteration of $K\left(\sigma_{-}\right)$and $M\left(\sigma_{-}\right)$.

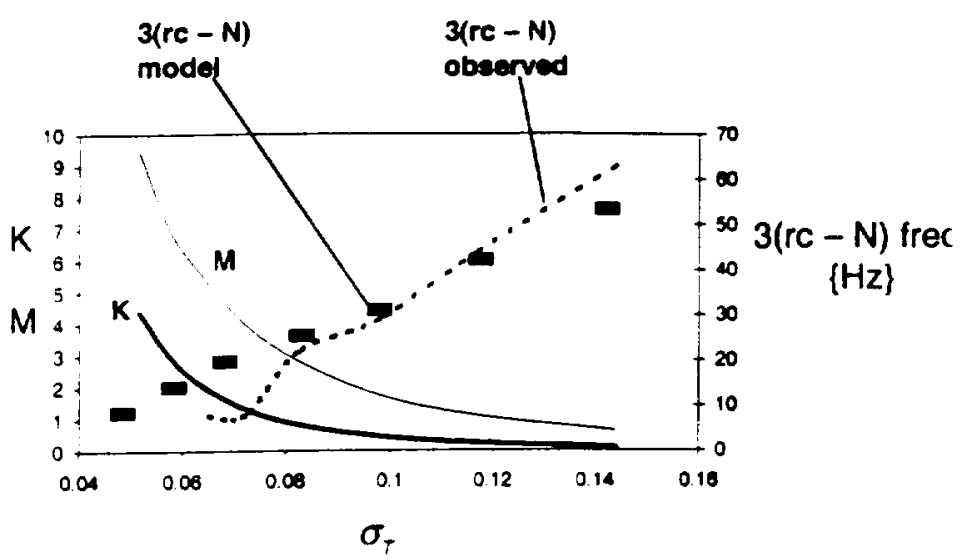

Figure 13. $K$ and $M$ Estimates versus $\sigma_{T}$, Based on Observed Frequency Variation of $3(r c-N)$

\section{System Stability Model Results}

A characteristic root of the system model with the pressure mode shape shown in Figure 14 was chosen to anchor $K$ and $M$ selection since it best matched observed amplitude distribution of the cavitation surge. Test data and audible observation showed the cavitation surge to be strongest in the vicinity of the inducer. The pressure mode. normalized by pump inlet pressure response, is plotted versus model element with flow direction going from left to right. Predicted critical damping ior the mode ranged from -0.20 at $12 \mathrm{kNss}$ to -0.52 at $26 \mathrm{kNss}$. Figure 13 also shows the frequency variation of the predicted mode versus $\sigma$. Interestingly, the most unstable modes predicted by the model consistently showed a mode shape similar to that of Figure 14, i.e. peak fluctuating pressure (and flow) at the inducer leading edge.

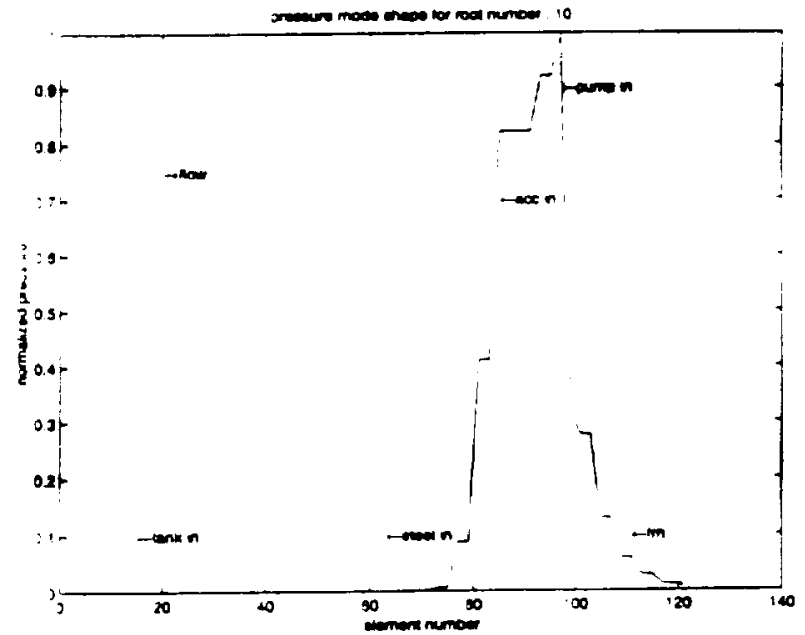

Figure 14. Predicted Mode Shape - Inducer Localized Instability 


\section{Concluding Remarks}

Fastrac LOX inducer rotating cavitation shares many of the complex features observed in other rocket engine turbomachines which have exhibited the same phenomenon.

The successful scaling of the oscillation between the water and LOX environments is encouraging.

The unique interaction between rotating cavitation and cavitation surge at the inducer inlet warrants further investigation. A better understanding of the flow features which induce such complex dynamic signatures will most likely enable the design of very high suction performance rocket turbomachines in the future.

The abundance of pump element assumptions made in the stability modeling attempt reflects the need for continuation of four-terminal. experimentally-derived, pump dynamic transier functions as pioneered by California Institute of Technology researchers in the 1970's. The severity of the cavitation-surge related damage to the Fastrac LOX inducer reinforces this need.

\section{Acknowledgments}

The author would like to thank those who contributed much to this paper: Steve Skelley. Herbert Bush. Mary Beth Koelbl, Tom Nesman (NASAMSFC); Jen Jong (AI Signal Research); and Sheldon Rubin (Rubin Engineerıng). Their contributions, both direct and indirect, are greatly appreciated.

\section{$\underline{\text { References }}$}

Skelley. S.. "Fastrac Liquid Oxvgen Turoopump Water Flow Test Plan (ITL0011)", NASAMSFC Internal Memorandum ED34(98-021), April 8, 1998.

2) Rosenmann, W., "Experimental Investigations of Hydrodynamically Induced Shaft Forces With a Three Bladed Inducer". ASME Symposium on Cavitation In Fluid Machinery, Winter Annual Meeting. November 1965. pp. 172-195.

3) Tsujimoto. $Y$. . et al., "Observations of Oscillating Cavitation of an Inducer", ASME
Journal of Fluids Engineering, December 1997, Volume 119, pp. 775-781.

4) Japikse, D., et al., “Experimental Test Results for Alternative SSME Hydrogen Turbopump Designs", Technical Memorandum No. 602, Contract No. NAS8-40648, February 1998, pp. 42-45.

5) Jong, J., et al., "Correlation Identification Between Spectral Components by Generalized Hypercoherence", $3^{\text {rd }}$ International Mach. Monitor. and Diag. Conf., December 1991.

6) Brennen, C., Acosta, A., “The Dynamic Transfer Function for a Cavitating Inducer", ASME Journal of Fluids Engineering, Volume 98, June 1976, pp. 182-191.

7) Oppenneim, B.. Rubin, S., "Advanced Pogo Stability Analysis for Liquid Rockets", Journal of Spacecraft and Rockets, Volume 30 No. 3 , 1993. pp. 360-373.

8) Ng, S., Brennen, C., "Experiments on the Dynamic Behavior of Cavitating Pumps", ASME Journat of Fluids Engineering. Volume 100. June 1978. pp. 166-176

9) NASA SP-194, "Liquid Propeliant Rocket Combustion Instability", 1972. page 110.

10) Tsujimoto. Y., Kamijo. K.. Brennen. C.. "Unified Treatment of Flow Instabilities of Turbomachines". AIAA Paper No. AIAA 99-2678. $35^{\text {in }}$ AIAAVASME/SAE/ASEE Joint Propulsion Conference and Exhibit, June 1999.

11) Ng, S., "Dynamic Response of Cavitating Turbomachines". NASA-CR-150036. August 1976.

12) Burton, K., private communication $K$. Burton to T. Zoladz, Fall 1999.

13) Zoladz, T., Powerpak Unsteady Flow Analysis Data Review Package, August 1999. 